\title{
Root Biomass Calculation Using a Modified Counting Technique
}

WILLIAM M. SCHAFER AND G.A. NIELSEN

\begin{abstract}
Data on root weight, length, and surface area are useful in soil characterization, ecosystem description, and studies of plant-soil interaction. Characterization of root systems is often thought to be so laborious and inaccurate that little data are collected. Root counts are used in soil surveys to evaluate root abundance; but these counts are not useful in most applications where data on roots are needed. An improved counting method provided root count data which correlated with measured root weight $\left(A W=0.97 \mathrm{PW}, \mathrm{r}^{2}\right.$ $=.85$ ) where $A W=$ actual weight and $P W=$ predicted weight. Counts were made in a dm² plexiglass frame parallel to the soil surface under short-and mid-grass prairie vegetation. As many as 30 samples were necessary to estimate root biomass within $25 \%(P<.10)$ with either root weighing or counting methods. Total root biomass calculated from root counts in the upper $100 \mathrm{~cm}$ of 15 southeastern Montana soils and in mine spoils ranged from 310 to $1,610 \mathrm{~g} / \mathrm{m}^{2}$ which is similar to published data on root biomass in other grassland communities.
\end{abstract}

In a study of 76 Hawaiian and Indian soils, Pandey (1969) found that cstimates of root abundance were highly correlated with precipitation, bulk density, organic carbon content, and other soil properties, and are therefore important in the prediction of many key soil properties. Hillel et al. (1976) and others used root length

Authors are research soil scientist and professor, Plant Soil Science Department, Montana State University, Bozeman 59717.

This report is a contribution of the Plant Soil Science Department, and the Montana Agr. Exp. Sta., Montana State University Manuscript No. 897. Research was funded in part by SEA-CR (USDA) Grant No. 684-15-4.

Manuscript received March 5, 1979. in models to predict water use from field soils (Newman 1966). Other workers have suggested root surface area should correlate with water and nutrient uptake. Changes in root biomass are sometimes measured as a component of ecosystem productivity (Bartos and Sims 1974). If root counting techniques (Soil Survey Staff 1975) could be correlated with other measures of root abundance, extensive data on root weight, length, and area could be obtained quickly through soil survey programs.

Characterization of the root systems of plants has long been a problem of agronomists, plant ecologists, and range scientists. Methods commonly used to investigate roots are laborious and often inaccurate. In a study of Montana soils, Decker (1972) found that root observations were often omitted from pedon descriptions. Lack of data on roots may indicate that estimation of root abundance is regarded as unimportant or difficult. In this paper we present a simple field method for rapidly collecting data on roots. A geometric model to calculate root weight from root counts is proposed.

\section{Materials and Methods}

Fifteen soils were selected for study in the Colstrip, Montana, area. Five pedons consisted of old strip-mined spoil, from 30- to 50 -years old, five pedons were newer spoils less than 10 years old, and five were undisturbed native range. Native soils were classified as Borollic Camborthids or Aridic Haploborolls and were sandy 


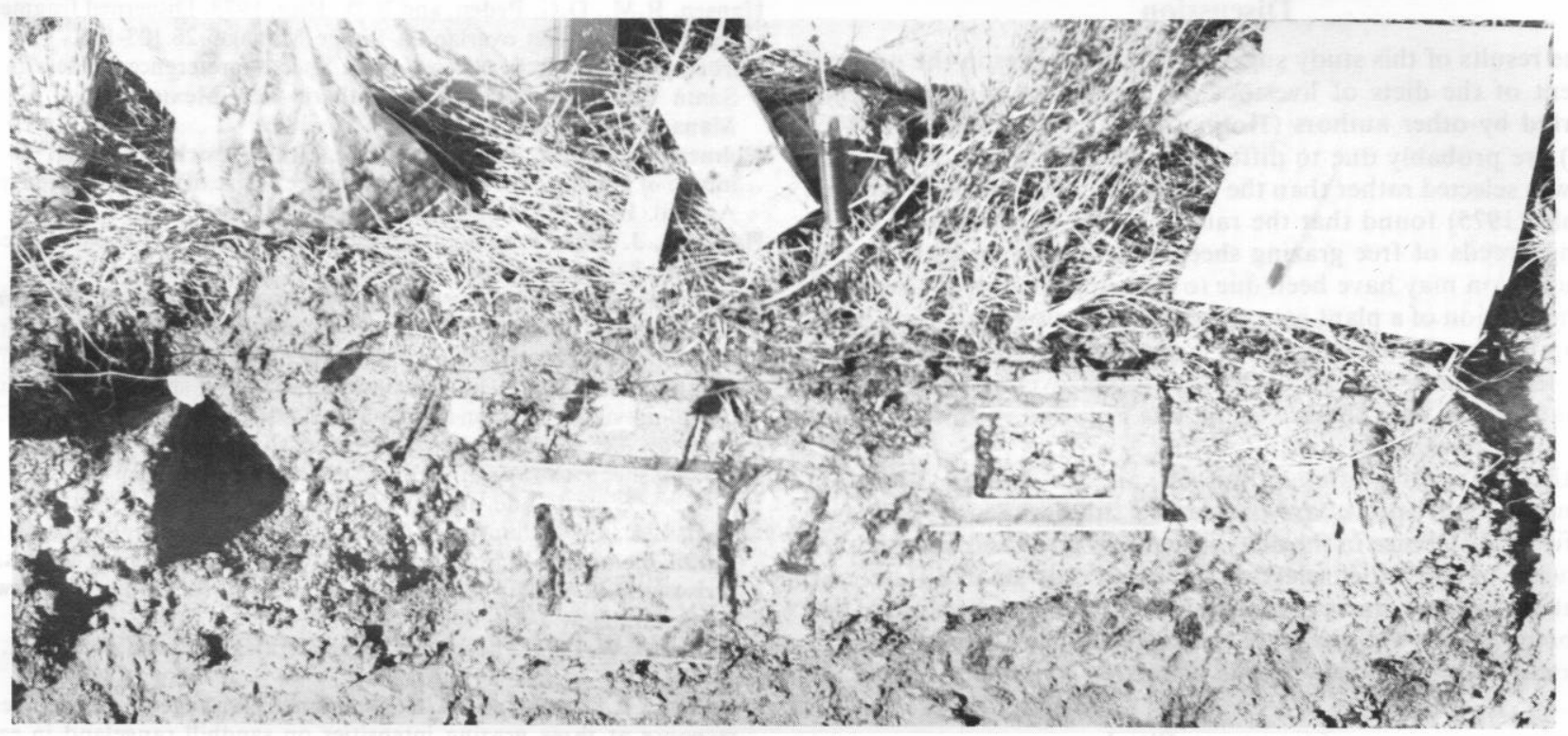

Fig. 1. A dm² plexiglass frame was used for counting roots at 10,50, and $100 \mathrm{~cm}$ in 15 soil profiles near Colstrip, Mt.

loam in texture (Schafer et al. 1977). Dominant vegetative types included mixed mid- and short-grass prairie, half-shrub communities, and mixed shrub-grasslands.

Backhoe pits were excavated and roots were counted in $\mathrm{dm}^{2}$ plexiglass frames at five randomly selected locations at the 10-, 50-, and 100-cm depths (Fig. 1). Roots in five different size classes were counted separately. Root diameter was visually estimated (Soil Survey Staff 1975).

$\begin{array}{clc}\text { Symbol } & \text { Class } & \text { Diameter }(\mathbf{m m}) \\ \text { MF } & \text { microfine } & \text { visible }-0.5 \\ \text { VF } & \text { very fine } & 0.5-1.0 \\ \text { F } & \text { fine } & 1-2 \\ \text { M } & \text { medium } & 2-5 \\ \text { C } & \text { coarse } & >5\end{array}$

Roots were counted in a horizontal plane which was perpendicular to the primary orientation of roots. After a count, a cube of soil 1 $\mathrm{dm}$ on each side was collected from the counting location for separation and weighing of roots. Roots were washed free of soil on a $1-\mathrm{mm}$ sieve and were weighed after oven-drying at $60^{\circ} \mathrm{C}$ for 48 hours and again after ignition at $600^{\circ} \mathrm{C}$ overnight. Root weights are reported on an ash-free basis (Table 1).

A geometric model was used to calculate root weight from root counts. Melhuish and Lang (1969) derived an equation to calculate root length density within the volume of a soil cube based on the number of roots intersecting a single face.

$$
\mathrm{L}=2 \mathrm{~N}
$$

where $\mathrm{N}$ is the number of roots crossing the cube face and $\mathrm{L}$ is the root length density in the cube in centimeters. Assuming that roots resemble cylinders in shape, then root volume in a cubic decimeter of soil can be calculated:

$$
\mathrm{V}=2 \mathrm{~N}\left(\pi \mathrm{r}^{2} \mathrm{H}\right)=20 \mathrm{~N}\left(\pi \mathrm{r}^{2}\right) .
$$

where $\mathrm{V}$ is root volume in $\mathrm{cm}^{3}, \mathrm{r}$ is the mean diameter in $\mathrm{cm}$, and $\mathrm{H}$ is the root height, which in the case of a cubic decimeter of soil would be $10 \mathrm{~cm}$. Root biomass for a single root size class can be calculated by multiplying root volume by root density. Finally root biomass from all size classes (microfine to coarse) can be summed to obtain total root biomass:

$$
\mathrm{W}=20 \mathrm{D} \stackrel{5}{\mathrm{~L}}=1_{\mathrm{y}}^{5} \pi \mathrm{r}^{2}
$$

Where $\mathrm{W}$ is the root weight in a cubic decimeter of soil and D is the root density in $\mathrm{g} / \mathrm{cm}^{3}, \mathrm{~N}_{\mathrm{y}}$ is the number of roots counted on the $\mathrm{y}^{\text {th }}$ size class, and $r_{y}$ is the mean diameter of roots in the $y^{\text {th }}$ size class (i.e. .03, .08, .15, .3, .5 cm).

\section{Results and Discussion}

\section{Predicted and Measured Root Weight}

Measured root weights were divided by root volumes calculated by equation (2) to find a value for $\mathrm{D}$, root density $\left(.12 \mathrm{~g} / \mathrm{cm}^{3}\right)$. When a density of $0.12 \mathrm{~g} / \mathrm{cm}^{3}$ was substituted in equation (3), the following relationship was found using a least squares linear regression for the data in Table 1 .

$$
\mathrm{AW}=0.97 \mathrm{PW} \quad r^{2}=0.85
$$

where AW was actual root weight and $\mathrm{PW}$ was predicted weight using equation (3). It is apparent that root weights predicted from root counts are highly correlated with weights obtained by the more time-consuming root separation technique. This suggests that root counting would be of value as a quick field test of root biomass.

\section{Number of Counts Needed to Estimate Root Abundance}

The number of counts ( $\mathrm{n}$ ) needed to predict a mean within given confidence limits (Snedecor and Cochran 1974) was used as a measure of the variability of the root weighing and root counting techniques (Table 2):

$$
\left(\mathrm{n}=4 \sigma^{2} / \mathrm{L}^{2}\right)
$$

Where $\mathrm{n}$ is the number of samples needed to estimate mean root biomass within specified confidence limits, $\mathrm{L}$, at $P=.90$, and $\sigma$ is the population standard deviation. Both root weighing and counting methods require extensive replication to give accurate root biomass estimates. The extreme variability of data on root abundance has also been reported by Schuurman and Goedewaagen (1965). The root weighing method is the most accurate near the soil surface while the counting method is more accurate below $10 \mathrm{~cm}$. For characterizing roots in a soil profile, an equal number of samples are needed with root counts as with the more laborious root weighing method.

Counts of the same soil area obtained by two different observers generally varied less than $10 \%$. Good lighting and careful observation were necessary for consistent recognition of the finest roots. Root counts obtained with the plexiglass frame and 
Table 1. Measured and predicted root weights $\left(\mathrm{g} / \mathrm{dm}^{3}\right)$ are shown by depth $(10,50$, and $100 \mathrm{~cm})$ in natural soils, 30-50-year-old minesoils, and $1-$ to 10-year- old minesoils. Total root biomass is expressed in $\mathrm{g} / \mathrm{m}^{2}$.

\begin{tabular}{|c|c|c|c|c|c|c|c|c|c|}
\hline \multirow[b]{2}{*}{$\begin{array}{l}\text { Depth } \\
\text { (cm) }\end{array}$} & \multirow[b]{2}{*}{$\begin{array}{l}\text { Site } 1 \\
\text { No. }\end{array}$} & \multicolumn{2}{|c|}{ Natural soils } & \multirow[b]{2}{*}{$\begin{array}{l}\text { Site } \\
\text { No. }\end{array}$} & \multicolumn{2}{|c|}{ Old minesoils } & \multirow[b]{2}{*}{$\begin{array}{l}\text { Site } \\
\text { No. }\end{array}$} & \multicolumn{2}{|c|}{ New minesoils } \\
\hline & & $\begin{array}{l}\text { Measured } \\
\text { root wt. }\end{array}$ & $\begin{array}{l}\text { Predicted } \\
\text { root wt. }\end{array}$ & & $\begin{array}{l}\text { Measured } \\
\text { root wt. }\end{array}$ & $\begin{array}{l}\text { Predicted } \\
\text { root wt. }\end{array}$ & & $\begin{array}{l}\text { Measured } \\
\text { root wt. }\end{array}$ & $\begin{array}{l}\text { Predicted } \\
\text { root wt. }\end{array}$ \\
\hline 10 & Chinook & $3.59^{2}$ & 2.04 & $1928-3$ & 3.30 & 1.31 & $1975-11$ & 1.23 & 1.12 \\
\hline 50 & 1 & .56 & .51 & & .27 & .11 & & .01 & .07 \\
\hline 100 & & .04 & .16 & & .13 & .08 & & .00 & .00 \\
\hline Total & & 1,198 & 845 & & 1,025 & 423 & & 313 & 315 \\
\hline 10 & Boxwell & 1.57 & 1.94 & $1928-5$ & 3.36 & 2.66 & $1973-12$ & 1.45 & 1.89 \\
\hline 50 & 2 & - & .16 & & .74 & 1.01 & & .06 & .10 \\
\hline 100 & & .00 & .06 & & .63 & .77 & & .04 & .02 \\
\hline Total & & 393 & 595 & & 1,525 & 1,555 & & 413 & 533 \\
\hline 10 & Ethridge & 2.01 & 1.12 & $1928-7$ & 2.18 & 3.89 & $1972-13$ & 2.23 & 3.56 \\
\hline 50 & 4 & .29 & .11 & & .09 & .29 & & .10 & .79 \\
\hline 100 & & .17 & .04 & & .04 & .04 & & .02 & .00 \\
\hline Total & & 733 & 355 & & 610 & 1,120 & & 564 & 1,285 \\
\hline 10 & Reidel & 4.29 & 3.41 & $1928-9$ & 1.68 & 1.73 & $1969-14$ & 1.66 & 1.16 \\
\hline 50 & 6 & .06 & .11 & & .12 & .19 & & .38 & .20 \\
\hline 100 & & .00 & .00 & & .05 & .23 & & .10 & .22 \\
\hline Total & & 1,103 & 908 & & 505 & 613 & & 655 & $\overline{500}$ \\
\hline 10 & Chinook & 3.35 & 3.04 & $1929-10$ & 2.94 & 3.58 & $1970-15$ & 1.74 & 1.28 \\
\hline 50 & 8 & .48 & .32 & & .61 & .85 & & .11 & .10 \\
\hline 100 & & .19 & .20 & & .17 & .58 & & .13 & .14 \\
\hline Total & & 1,173 & 1,020 & & 1,125 & 1,610 & & 555 & 440 \\
\hline
\end{tabular}

ISite names represent either the soil series name for the natural soils or date of last disturbance of the minesoils.

${ }^{2}$ Data presented represent the mean of five root weights $\left(\mathrm{g} / \mathrm{dm}^{3}\right)$ at 10,50 , and $100 \mathrm{~cm}$. Total profile root weight, expressed in $\mathrm{Kg} /$ ha are a weighted average of root biomass at the above depths.

Table 2. Number of counts needed to estimate mean root weight within $25 \%$ with $95 \%$ probability.

\begin{tabular}{ccc}
\hline \hline Depth $(\mathrm{cm})$ & Root weight method & Root count method \\
\hline 10 & 7 & 15 \\
50 & 30 & 30 \\
100 & 44 & 28 \\
\hline
\end{tabular}

modified counting technique proposed were compared to root estimates made by experienced soil scientists using the standard SCS method (Soil Survey Staff 1975). The standard method underestimated root abundance by a full class (few, common, or many) in $22 \%$ of the observations.

\section{Field Application}

Roots were counted as previously described at 10-, 50-, and 100$\mathrm{cm}$ in 15 soils near Colstrip, Montana. Only 15 minutes were required to characterize the roots in each pedon.

Root biomass was calculated using equation (3) based on root numbers in horizontal plane (root/ $\mathrm{dm}^{2}$ ). Total profile root biomass (upper $100 \mathrm{~cm}$ ) obtained by this method (Table 1) ranged from $310-1,610 \mathrm{~g} / \mathrm{m}^{2}$. Most root weights were $\left(1,000-1,500 \mathrm{~g} / \mathrm{m}^{2}\right)$ similar to published data for the Colorado short-grass prairie: 1,600-1,800 g/ $\mathrm{m}^{2}$ (Bartos and Sims 1974; Singh and Coleman 1974), Missouri tall-grass prairie: $1,400-1,900 \mathrm{~g} / \mathrm{m}^{2}$ (Dahlman and Kucera 1965), and Utah cool desert communities: 1,600-1,800 $\mathrm{g} / \mathrm{m}^{2}$, (Caldwell and Camp 1974). Average root biomass in the upper $10 \mathrm{~cm}\left(340 \mathrm{~g} / \mathrm{m}^{2}\right)$ found in this study was similar to that found during late summer by Lauenroth et al. (1976) in the Colstrip area.

\section{Literature Cited}

Bartos, D.L., and P.L. Sims. 1974. Root dynamics of a shortgrass ecosystem. J. Range Manage. 27:33-36.

Caldwell, M.M., and L.B. Camp. 1974. Belowground productivity of two cool desert communities. Oecologia 17:123-130.

Dahlman, R.C., and C.L. Kucera. 1965. Root productivity and turnover in native prairie. Ecology 46:84-89.

Decker, G.L. 1972. Automatic retrieval and analysis of soil characterization data. Ph.D. Thesis. Montana State Univ. Microfilms. Ann Arbor, Mich. (Diss. Abstr. 73:10949).

Hillel, D., H. Talpaz, and H. Van Keulan. 1976. A macroscopic-scale model of water uptake by a nonuniform root system and of water and salt movement in the soil profile. Soil Sci. 121:242-255.

Lauenroth, W.K., J.L. Dodd, R.K. Heitschmidt, and R.G. Woodmansee. 1976. Biomass dynamics and primary production in mixed prairie grasslands in southeastern Montana: Baseline data for air pollution studies. In: The Bioenvironmental Impact of a Coal-fired Power Plant. 2nd interim rep. EPA 600/3-76-013, p. 227-255.

Melhuish, F.M., and A.R.G. Lang. 1969. A new technique for estimating diameter, total length and surface area of roots grown in soil. In: Whitington, W.J. (ed.) Root Growth. p. 397-398. Plenum Press, N.Y.

Newman, E.I. 1966. A method of estimating the total length of root in a sample. J. Appl. Ecol. 3:139-145.

Pandey, S.J. 1969. Prediction and comparison of properties of Hawaiian and Indian Red Earths using automatic data processing techniques. Ph.D. Diss., University of Hawaii, Honolulu.

Schafer, W.M., G.A. Nielsen, and D.J. Dollhopf. 1977. Soil genesis, hydrological properties, and root characteristics of 2 to 53-year-old stripmine spoils. Montana Agr. Exp. Sta. Res. Rep. 108.

Schuurman, J.J., and M.A.J. Goedwaagen. 1965. Methods for the examination of root systems and roots. Centre for Agr. Publ. Wangeningen. Groningen, Netherlands $86 \mathrm{p}$.

Singh, J.S., and D.C. Coleman. 1974. Distribution of photo-assimilated ${ }^{14}$ carbon in the root system of a short grass prairie. J. Ecol. 62:359-365.

Snedecor, G.W., and W.G. Cochran. 1974. Statistical Methods. 6th ed. Iowa State University Press, Ames. 593 p.

Soil Survey Staff. 1975. Soil Taxonomy. Agr. Handb. No. 436. USDA. U.S. Government Printing Office, Washington, D.C. 754 p. 